\title{
Mandibular Branch of the Facial Nerve in Wistar Rats: New Experimental Model to Assess Facial Nerve Regeneration
}

\author{
Ricardo Ferreira Bento ${ }^{1}$ Raquel Salomone ${ }^{1}$ Silvia Bona do Nascimento ${ }^{2}$ \\ Ricardo Jose Rodriguez Ferreira ${ }^{2}$ Ciro Ferreira da Silva ${ }^{3}$ Heloisa Juliana Zabeu Rossi Costa ${ }^{1}$
}

${ }^{1}$ Department of Ophthalmology and Otolaryngology, Universidade de São Paulo, São Paulo, SP, Brazil

2 Department of Orthopedics and Trauma, Universidade de São Paulo, São Paulo, SP, Brazil

${ }^{3}$ Department of Cell and Developmental Biology, Universidade de São

Address for correspondence Silvia Nascimento, Department of Otorinolaringologia, Instituto de Neurociencias, Rua Bartolomeu Vasconcelos 2440 Bairro Ilhotas, Teresina, Piaui 64049570, Brazil (e-mail: silviabona@yahoo.com).

Paulo, São Paulo, SP, Brazil

Int Arch Otorhinolaryngol 2014;18:277-282.

\begin{abstract}
Keywords

- facial nerve

- electromyography

- nerve regeneration

- histologic analysis

Introduction The ideal animal model for nerve regeneration studies is the object of controversy, because all models described by the literature have advantages and disadvantages.

Objective To describe the histologic and functional patterns of the mandibular branch of the facial nerve of Wistar rats to create a new experimental model of facial nerve regeneration.

Methods Forty-two male rats were submitted to a nerve conduction test of the mandibular branch to obtain the compound muscle action potential. Twelve of these rats had the mandibular branch surgically removed and submitted to histologic analysis (number, partial density, and axonal diameter) of the proximal and distal segments.

Results There was no statistically significant difference in the functional and histologic variables studied.

Conclusion These new histologic and functional standards of the mandibular branch of the facial nerve of rats establish an objective, easy, and greatly reproducible model for future facial nerve regeneration studies.
\end{abstract}

\section{Introduction}

To study the processes that affect facial nerve degeneration and regeneration, several experimental models were created. Large animals such as pigs have a long vertical (mastoid) segment of the facial nerve, great for surgical procedures but difficult to use because of their handling, high maintenance costs, and small resistance to infections, ${ }^{1}$ besides having a high incidence of anesthetic complications. ${ }^{2}$ Medium to small mammals such as cats, rabbits, and guinea pigs are easier to handle and cost less compared with large animals, ${ }^{2}$ have facial nerves that anatomically resemble the human facial nerve, ${ }^{2,3}$ and have well-known reactions to posttraumatic microbiological exposure. ${ }^{4}$ However, such animals are relatively difficult to handle and maintain, are more prone to infections, and are less tolerant to bilateral facial paralysis. ${ }^{1,2}$ At the same time, small animals such as rats are being widely employed in experimental research for their advantages, such as easy caretaking and handling, high resistance to infections and interventions, low-cost and convenient housing, besides having well-described growth, anatomic, and metabolic parameters. ${ }^{1,2,5,6}$ Regarding facial nerve studies, rats endure well bilateral facial paralysis and exhibit similar anatomic nerves as primates. ${ }^{5}$ received

November 18, 2013 accepted

December 11, 2013

published online

May 23, 2014
DOI http://dx.doi.org/

10.1055/s-0034-1366977. ISSN 1809-9777.
Copyright $\odot 2014$ by Thieme Publicações License terms Ltda, Rio de Janeiro, Brazil 
One of the most used experimental models of peripheral nerve regeneration involves the sciatic nerve of rats, mainly because of its easy exposure and long extension. ${ }^{6,7}$ However, this nerve divides itself after leaving the sacrum, possibly altering the results of functional or histologic investigations. ${ }^{1-5,8,9}$ Furthermore, authors such as Aldskogius et al, ${ }^{10}$ Labelle and Allen, ${ }^{11}$ McCoy and Boyle, ${ }^{12}$ Spector et al, ${ }^{13}$ and Szal and Miller ${ }^{14}$ refer that, because of its long path inside a bony canal, the facial nerve has remarkable differences in regeneration and therefore cannot be compared with the sciatic nerve.

Electrophysiologic studies have the purpose of quantifying the function, and, therefore, investigating the pathologies of the peripheral nervous system, especially of the sensitive and motor neurons, the neuromuscular junction, and the motor unit. Hence, they are a fundamental part of experimental models that aim to evaluate nerve regeneration. ${ }^{5}$ Methods of subjective and noninvasive evaluation of the facial nerve have been created, such as the "walking track," related to the sciatic nerve. Facial mimics observation scales, ${ }^{8}$ precise videotaping of facial movements, ${ }^{14}$ and muscle fibrillation ${ }^{15}$ sometimes associated to scales are examples of widely used methods of functional facial nerve evaluation. However, all these methods are subjective and, thus, altered when performed by distinct examiners or in the presence of postsurgical scars or edema. ${ }^{16}$

Nerve morphometric studies, which include counting of axons and of axonal density and diameter, are considered by many authors an objective method of evaluating nerve regeneration. ${ }^{14-17}$ Qualitative analysis, although being a subjective method, can be associated to quantitative analysis to determine the quality of regenerated nerve tissue, especially in a time-dependent manner, adding precision to the experimental results. ${ }^{4}$

Therefore, this experimental study aims to describe the qualitative and quantitative histologic patterns and motor neuroconduction patterns by electroneuromyography of the mandibular branch of the facial nerve of Wistar rats, to create a new experimental model for facial nerve regeneration studies, that is both objective and thorough.

\section{Materials and Methods}

All experiments were conducted according to the Guide for the Care and Use of Laboratory Animals, ${ }^{18}$ after approval by the institution's ethics committee under protocol number 0291/07.

Functional evaluation included electroneuromyography of the mandibular branch of the facial nerve of rats. Forty-two male Wistar rats, weighing 250 to $300 \mathrm{~g}$, with body temperatures ranging from 34.5 to $36.5^{\circ} \mathrm{C}$, were anesthetized by an intraperitoneal injection of $10 \%$ chloral hydrate at $400 \mathrm{mg} / \mathrm{kg}$ and subjected to neurophysiologic evaluation by a motor neuroconduction test of the mandibular branch of the facial nerve to obtain the compound muscle action potential (CMAP) for posterior analysis of its latency, amplitude, and duration.

The motor neuroconduction test was performed according to method previously described by Salomone et al and consists of obtaining CMAPs by supramaximal stimulation of the mandibular branch, identified by transparency, through the skin at a distance of $20 \mathrm{~mm}$ from the labial commissure. ${ }^{5}$ The recording electrodes are two subdermal needle electrodes, separated by $5 \mathrm{~mm}$ and located $2 \mathrm{~mm}$ from the lower lip and labial commissure.

To prevent the influence of anatomic variations on electrical signals, all animals presenting branches of the mandibular nerve to the upper lip or branches of the buccal nerve to the lower lip or branches that connected the two were excluded.

Histologic evaluation included qualitative and quantitative study of the mandibular branch of the facial nerve of rats. Twelve rats, randomly chosen after electroneuromyography, were subjected to dissection, in situ fixation, and removal of the mandibular branch of the facial nerve, according to method described by Costa et al. ${ }^{19}$ This method consists of removing $3 \mathrm{~mm}$ of the previously fixated nerve by two transversal incisions, made 25 and $28 \mathrm{~mm}$ from the labial commissure. Therefore, a nerve segment with two endsdistal (D) and proximal (P)-is produced. After removal, nerve segments were treated with a $2 \%$ osmium solution, dehydrated with ethanol, infiltrated with propylene oxide, and embedded in Epoxi resin (Burlington, Vermont, United States) until polymerization. After these steps, $\mathrm{P}$ and D segments were cut into smaller ones of $0.5 \mu \mathrm{m}$ in width and stained with $1 \%$ toluidine blue.

For nerve documentation, slides with $\mathrm{P}$ and D segments were photographed (Nikon Coolpix E 955, Nikon Corporation, Tokyo, Japan) with an optical microscope using $50 \times$ magnification (one field to view the entire nerve) and $400 \times$ magnification (three fields of $3,000 \mu \mathrm{m}^{2}$, comprising a total area of $9,000 \mu \mathrm{m}^{2}$ ). Afterward, images were transferred to a portable computer and analyzed by SigmaScan Pro 5.0 (Statistical Package for Social Sciences [SPSS] Science, Chicago, Illinois, United States).

Photographs obtained with the $50 \times$ magnification were used for evaluation of the qualitative aspects of nerve segments, namely, quantity of fascicles and axonal arrangement (morphometry and distribution of myelinated axons).

Quantitative evaluation of P and D segments was performed with three images obtained with the $400 \times$ magnification and involved analyzing the total number of myelinated axons in a $9,000-\mu \mathrm{m}^{2}$ nerve area, the partial density of myelinated axons (partial quantity of myelinated axons/partial area $\left.\left[9,000 \mu \mathrm{m}^{2}\right]\right)$, and myelin maturation by measuring the smallest outer nerve diameter (including the myelin sheath) in the $9,000-\mu \mathrm{m}^{2}$ area.

\section{Statistical Analysis}

The Wilcoxon signed rank test from the SPSS software, version 21.0, was used to assess differences $(p<0.05)$ in values of CMAP latency, amplitude, duration, area, and intensity and in total axon number, axonal diameter, and axonal density of $\mathrm{P}$ and $\mathrm{D}$ segments obtained from each side.

\section{Results}

- Table 1 compares means, medians, standard deviations, and percentiles of amplitude, latency, duration, and intensity of 
Table 1 Comparison of the values of amplitude, latency, duration, and intensity of CMAPs obtained in the left and right sides of the mandibular branch of the facial nerve of Wistar rats

\begin{tabular}{|c|c|c|c|c|c|c|c|c|c|c|}
\hline CMAP variable & Side & $n$ & $\begin{array}{l}\text { Mean } \\
\text { value }\end{array}$ & $\begin{array}{l}\text { Standard } \\
\text { derivation }\end{array}$ & $\begin{array}{l}\text { Lower } \\
\text { limit }\end{array}$ & $\begin{array}{l}\text { Higher } \\
\text { limit }\end{array}$ & $\begin{array}{l}\text { 25th } \\
\text { percentile }\end{array}$ & Median & $\begin{array}{l}\text { 75th } \\
\text { percentile }\end{array}$ & $p$ value $^{a}$ \\
\hline \multirow[t]{2}{*}{ Amplitude (mV) } & Right & 42 & 5.8 & 1.89 & 2.52 & 10.67 & 4.32 & 5.78 & 7 & \multirow[t]{2}{*}{0.871} \\
\hline & Left & 42 & 5.76 & 1.9 & 1.59 & 9.08 & 4.24 & 6.03 & 7.23 & \\
\hline \multirow[t]{2}{*}{ Latency (ms) } & Right & 42 & 1.17 & 0.28 & 0.58 & 2.05 & 1.02 & 1.18 & 1.34 & \multirow[t]{2}{*}{0.613} \\
\hline & Left & 42 & 1.15 & 0.31 & 0.6 & 2.66 & 1.02 & 1.1 & 1.30 & \\
\hline \multirow[t]{2}{*}{ Duration (ms) } & Right & 42 & 4.46 & 1.08 & 2.06 & 6.83 & 3.71 & 4.46 & 5.09 & \multirow[t]{2}{*}{0.990} \\
\hline & Left & 42 & 4.41 & 8.83 & 2.62 & 6.08 & 3.94 & 4.37 & 4.79 & \\
\hline \multirow[t]{2}{*}{ Stimulus (mA) } & Right & 42 & 2.73 & 0.65 & 1.7 & 4.5 & 2.08 & 2.70 & 3 & \multirow[t]{2}{*}{0.514} \\
\hline & Left & 42 & 2.46 & 0.52 & 1.5 & 4 & 2 & 2.5 & 3 & \\
\hline
\end{tabular}

Abbreviation: CMAP, compound muscle action potential.

ailcoxon signed rank test.

CMAPs obtained from each side. There were no statistically significant differences between sides.

Qualitative histologic evaluation of P and D segments showed no noticeable differences. All segments had two to three well-defined fascicles (-Figs. 1A, B), with normal axons, exhibiting similar diameter and homogeneous distribution (-Figs. 1C, D). The segment's perineurium exhibited condensed loose tissue and the epineurium was visibly preserved (-Figs. 1A-D).
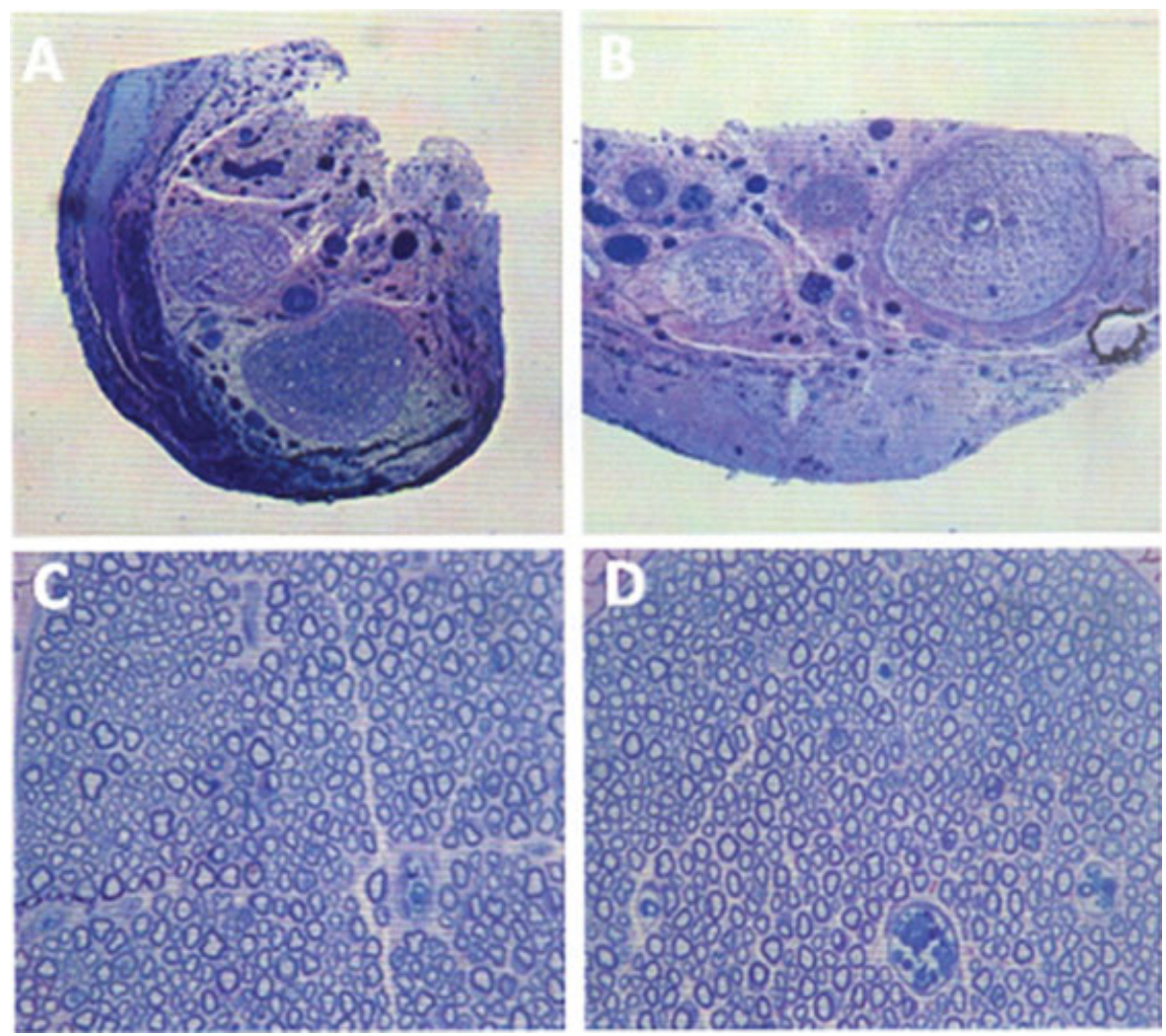

Fig. 1 Images obtained by optical microscopy. Visualization of the proximal segment in the lesser magnification $(A, 50 \times)$ and greater magnification $(C, 400 \times)$ and of the distal segment in the lesser magnification $(B, 50 \times)$ and greater magnification $(D, 400 \times)$. 
Table 2 Comparison of the number, diameter, and density of axons obtained in the proximal and distal segments

\begin{tabular}{|c|c|c|c|c|c|c|c|c|c|c|}
\hline Axonal & Segment & $n$ & $\begin{array}{l}\text { Mean } \\
\text { value }\end{array}$ & $\begin{array}{l}\text { Standard } \\
\text { derivation }\end{array}$ & $\begin{array}{l}\text { Lower } \\
\text { limit }\end{array}$ & $\begin{array}{l}\text { Higher } \\
\text { limit }\end{array}$ & $\begin{array}{l}\text { 25th } \\
\text { percentile }\end{array}$ & Median & $\begin{array}{l}\text { 75th } \\
\text { percentile }\end{array}$ & $p$ value $^{a}$ \\
\hline \multirow[t]{2}{*}{ Number } & Proximal & 12 & 1,662 & 131.03 & 1,336 & 1,847 & $1,590.75$ & $1,669.5$ & 1,753 & \multirow[t]{2}{*}{0.666} \\
\hline & Distal & 12 & 1,646 & 115.96 & 1,382 & 1,789 & 1,599 & 1,663 & $1,721.5$ & \\
\hline \multirow{2}{*}{$\begin{array}{l}\text { Density } \\
\text { (number/ } \mathrm{mm}^{2} \text { ) }\end{array}$} & Proximal & 12 & 0.18 & 0.01 & 0.15 & 0.21 & 0.18 & 0.19 & 0.19 & \multirow[t]{2}{*}{0.666} \\
\hline & Distal & 12 & 0.18 & 0.01 & 0.15 & 0.2 & 0.18 & 0.18 & 0.19 & \\
\hline \multirow[t]{2}{*}{ Diameter $(\mu \mathrm{m})$} & Proximal & 12 & 4.5 & 0.21 & 4.2 & 5.01 & 4.36 & 4.48 & 4.53 & \multirow[t]{2}{*}{0.937} \\
\hline & Distal & 12 & 4.49 & 0.27 & 4.09 & 5.06 & 4.28 & 4.51 & 4.61 & \\
\hline
\end{tabular}

${ }^{a}$ Wilcoxon signed rank test.

present as small animals (described in the introduction) but also because they have a very long and purely motor extratemporal segment of the facial nerve, which is easy to access and divides itself similarly in all rodents. Another advantage is that, in Wistar rats, the facial nerve passes below and not inside the parotid gland, and its peripheral branches lay above the superficial facial fascia, simplifying exposure and dissection. ${ }^{2,7,20}$ Additionally, the facial nerve fibers do not vary according to animal weight or age. ${ }^{2-20}$ Male rats were chosen because of the proven effect that female hormones have on nerve regeneration. ${ }^{21}$

The mandibular branch was chosen because of some unique qualities: (1) easy access compared with other branches such as the posterior auricular, cervical, temporal, and zygomatic branches ${ }^{2,23-25}$; (2) longer path $(10$ to $12 \mathrm{~mm})$ before splitting compared with the facial nerve trunk ( $6 \mathrm{~mm})$ and to its posterior cervical, cervical, buccal, auriculotemporal, zygomatic, and temporal branches, allowing surgical manipulation and graft alignment with reliable results ${ }^{2-5,8,9}$; (3) less complex anatomy compared with the temporal and zygomatic branches ${ }^{2-22} ;$ (4) visualization of the nerve through the skin, previous to surgical intervention, avoiding operations on animals with anatomic variations, such as branches to the upper lip, other additional branches, or anastomosis with the buccal branch of the facial nerve, which could jeopardize the results of electrophysiologic tests ${ }^{5}$; (5) homogeneous histology $2,19,23$; (6) highly reproducible nervous conduction tests ${ }^{5}$; and (7) resemblance to the human facial nerve, including the presence of nerve fascicles. ${ }^{2,23,25}$

To create an objective method of functional evaluation of the facial nerve of rats, several methods were described. Mattox and Felix were pioneers in stimulating the facial nerve in multiple segments (trunk, buccal and mandibular branches) and registered answers with subcutaneous electrodes located on the upper and lower lips of rats. ${ }^{2}$ Several years later, Byrne et al stimulated the facial nerve trunk and registered the CMAPs using electrodes located bilaterally and symmetrically near the whiskers. ${ }^{23}$ Posteriorly, Shi et al evaluated only the buccal branch of the facial nerve, inserting it through a silicone tube, stimulating the proximal segment and registering the answer with microneedles in the distal segment to obtain the nerve's action potential. ${ }^{24}$ However, besides being invasive, all the methods above failed to establish an exact place for the stimulus, which can cause distortion of distance-dependent results, such as latency and duration of CMAPs. ${ }^{25,26}$

Another important topic to discuss regarding functional evaluation methods by electroneuromyography is the intensity of the stimulus. Amplitude is directly proportional to the number and synchrony of intact axonal fibers that the stimulus depolarizes. ${ }^{7,28,29}$ Therefore, below normal amplitude may occur because of the reduction of number or synchrony of preserved fibers or because of a low stimulus. Hence, it is necessary to establish a standard of stimulus intensity. In this sense, the supramaximal stimulus, which is the minimum intensity necessary to depolarize all the nerve fibers plus 20\%, ${ }^{5-7,10-25,27-29}$ is ideal. ${ }^{1,28,29}$ Mattox and Felix ${ }^{2}$ did not describe the intensity of the stimulus used. Shi et al used a constant current of $0.5 \mathrm{~mA},{ }^{24}$ and Byrne et al found a supramaximal stimulus of $1.5 \mathrm{~mA},{ }^{23}$ different from the value that our group obtained in a series of experiments. ${ }^{5-7,10-30}$

Anatomical variations also demand caution. As previously described, the mandibular branch of the facial nerve of Wistar rats can give branches to the upper lip, anastomosing the mandibular and buccal branches. ${ }^{2,23-25}$ This fact was confirmed by Mattox and Felix when they stimulated the buccal and mandibular branches separately and detected synchronic answers in electrodes located in the upper and lower lips. ${ }^{2}$ However, the same authors demonstrated that the CMAPs produced by the mandibular branch (lower lip) have a broader trace but lower amplitudes when compared with those of the buccal branch (upper lip). Visualization of the nerve before surgery, through the skin, helps exclude animals with anatomical variations.

Our results show that there were no statistically significant differences in values of amplitude, latency, duration, and intensity of CMAPs when left and right sides were compared. The values obtained for these variables were compatible with those standardized by Salomone et $\mathrm{al}^{5}$ and endorsed by Costa et al, ${ }^{30}$ demonstrating that this objective evaluation method is highly reproducible.

In regard to the histologic studies, authors disagree about the best quantitative morphometric parameter to evaluate nerve regeneration. According to Hubbard ${ }^{31}$ and Vasconcelos and Gay-Escoda, ${ }^{32}$ the total axon number is the most important criterion. For Miyamoto, 33 axonal density is the most 
important variable. Meanwhile, Donovan, ${ }^{34}$ Duncan, ${ }^{35}$ Fernand and Young, ${ }^{36}$ and Williams and Wendell-Smith ${ }^{37}$ defend that nerve fiber diameter is the most reliable parameter to compare experimental groups and individuals in the same experimental group. May and Schaitkin support that both axonal diameter and the width and length of the myelin sheath are the most relevant factors regarding histologic nerve recovery. ${ }^{38}$

According to Harrison, ${ }^{39}$ the analysis of morphometric characteristics of myelinic fibers can be accomplished with software, simplifying counting and also yielding precise and reliable results. Furthermore, it is unnecessary to evaluate the morphometric characteristics of the entire nerve, because the results obtained in $6 \%$ of the total area are as precise as those of the whole area of myelinic fibers of a nerve. ${ }^{40,41}$

In this study, the partial area analyzed $\left(9,000 \mu \mathrm{m}^{2}\right)$ represents almost $90 \%$ of the total area of the mandibular branch of the facial nerve of Wistar rats. ${ }^{19}$ The morphometric histologic data (total axon number, axonal density, and

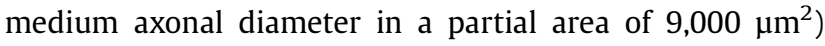
were analyzed by two independent and blind examiners, using the SigmaScan Pro 5.0 software (SPSS Science), and the final data represent the medium value of that obtained from the two examiners. The fibers that had centers out of the microscope's field were excluded to avoid the edge effect and any possible resultant sampling errors. ${ }^{42,43}$

Mattox and Felix described that normal mandibular branches of the facial nerve of Wistar rats contain between three and five fascicles. ${ }^{2}$ Our results show that the number of fascicles varied between two and three, up to their insertion in the lower lip muscle. However, the results obtained in the quantitative and qualitative histologic studies (number of axons, axonal density, and diameter) of the $\mathrm{P}$ and $\mathrm{D}$ segments were similar to those described by Mattox and Felix, ${ }^{2}$ Costa et $\mathrm{al}^{19,30}$ and Salomone et al, ${ }^{44}$ indicating that the mandibular branch of the facial nerve of Wistar rats varies very little between sides and animals, besides being more similar to the human facial nerve when compared with the facial nerve trunk, qualifying as an adequate model for the study of facial nerve regeneration.

On the other hand, according to Ochi et al, ${ }^{45}$ the results obtained with histologic methods of neural regeneration, despite being qualitative, quantitative, or both, must be analyzed with caution, because the increase in the size or quantity of axons may not correspond to functional improvement. Regarding this, the authors note that species with many myelinated small axons or few myelinated large axons behave similarly during regeneration. Grosheva et al are even more extreme, claiming that axonal quantity, density, and diameter have no importance if axonal growth is not directed toward the motor end plate. ${ }^{15}$

\section{Conclusions}

With histologic (qualitative and quantitative) and functional (nerve conduction studies) standardization of the mandibular branch of the facial nerve of rats, we obtained a novel experimental model, which is objective, easy, and highly reproducible, for future facial nerve regeneration studies.

\section{References}

1 Barrs DM. Facial nerve trauma: optimal timing for repair. Laryngoscope 1991;101(8):835-848

2 Mattox DE, Felix H. Surgical anatomy of the rat facial nerve. Am J Otol 1987;8(1):43-47

3 Bento RF. Contribuição para o estudo da anastomose do nervo facial. Comparação entre o adesivo tecidual fibrínico e a sutura epineural. Estudo em gatos. São Paulo, Brazil: Faculdade de Medicina, Universidade de São Paulo; 1988

4 Costa HJZR. Estudo experimental sobre a regeneração pós-traumática do nervo facial em coelhos. São Paulo, Brazil: Faculdade de Ciências Médicas da Santa Casa de São Paulo; 2003

5 Salomone R, Costa HJZR, Rodrigues JR, Reis e Silva SM, Ovando PC, Bento RF. Assessment of a neurophysiological model of the mandibular branch of the facial nerve in rats by electromyography. Ann Otol Rhinol Laryngol 2012;121(3):179-184

6 Dezawa M, Takahashi I, Esaki M, Takano M, Sawada H. Sciatic nerve regeneration in rats induced by transplantation of in vitro differentiated bone-marrow stromal cells. Eur J Neurosci 2001;14(11): 1771-1776

7 Seckel BR, Chiu TH, Nyilas E, Sidman RL. Nerve regeneration through synthetic biodegradable nerve guides: regulation by the target organ. Plast Reconstr Surg 1984;74(2):173-181

8 Borin A, Toledo RN, Faria SD, Testa JR, Cruz OL. Behavioral and histologic experimental model of facial nerve regeneration in rats. Braz J Otorhinolaryngol 2006;72(6):775-784

9 Donaldson HH. The rat: Data and reference tables for the albino rat (Mus norvegius albinus) and the norway rat (Mus norvegius). J Comp Neuro 1912;22:71-72

10 Aldskogius H, Barron KD, Regal R. Axon reaction in dorsal motor vagal and hypoglossal neurons of the adult rat. Light microscopy and RNA-cytochemistry. J Comp Neurol 1980;193(1):165-177

11 Labelle JJ, Allen DE. The peripheral nerve repair. A review. J Maine Med Assoc 1972;63(8):164-166

12 McCoy EG, Boyle WF. Reinnervation of the facial muscles following extratemporal facial nerve resection. Laryngoscope 1971;81(1): $1-7$

13 Spector JG, Lee P, Derby A. Rabbit facial nerve regeneration in autologous nerve grafts after antecedent injury. Laryngoscope 2000;110(4):660-667

14 Szal GJ, Miller T. Surgical repair of facial nerve branches. An analysis of diferente sheathing and suturing techniques. Arch Otolaryngol 1975;101(3):160-165

15 Grosheva M, Guntinas-Lichius O, Arnhold S, et al. Bone marrowderived mesenchymal stem cell transplantation does not improve quality of muscle reinnervation or recovery of motor function after facial nerve transection in rats. Biol Chem 2008;389(7): 873-888

16 Stipp-Brambilla EJ, Romão AM, Garbino JA, Salgado MH, Viterboz F. Efeito da exposição cirúrgica de nervos e músculos no teste neurofisiológicos em ratos. Acta Fisiatr 2010;17(3):109-111

17 Lewin SL, Utley DS, Cheng ET, Verity AN, Terris DJ. Simultaneous treatment with BDNF and CNTF after peripheral nerve transection and repair enhances rate of functional recovery compared with BDNF treatment alone. Laryngoscope 1997;107(7):992-999

18 National Research Council. Institute of Laboratory Animal Resources. Comission on life sciences. Manual sobre Cuidados e Usos de Animais de Laboratório. Goiânia: AAALAC/COBEA; 2003

19 Costa HJZR, Salomone R, Silva CF, Costa MP, Ramos BL, Bento RF. Quantitative histological analysis of the mandibular branch of the facial nerve in rats. Acta Cir Bras 2012;27(11):747-750

20 Semba K, Egger MD. The facial "motor" nerve of the rat: control of vibrissal movement and examination of motor and sensory components. J Comp Neurol 1986;247(2):144-158

21 Kinderman NB, Jones KJ. Axotomy-induced changes in ribosomal RNA levels in female hamster facial motoneurons: differential effects of gender and androgen exposure. Exp Neurol 1994;126(1): 144-148 
22 Hebel R, Stromberg MW. Anatomy of the Laboratory Rat. Baltimore, MD: Williams \& Wilkins; 1976

23 Byrne PJ, Stuart RM, Fakhry C, Lehar M, Flint PW. An electrophysiologic model for functional assessment of effects of neurotrophic factors on facial nerve reinnervation. Arch Facial Plast Surg 2005; 7(2):114-118

24 Shi Y, Zhou L, Tian J, Wang Y. Transplantation of neural stem cells overexpressing glia-derived neurotrophic factor promotes facial nerve regeneration. Acta Otolaryngol 2009;129(8):906-914

25 Liverson JA, Dong MM. Laboratory Reference for Clinical Neurophysiology. Philadelphia, PA: Davis Company; 1992

26 Nobrega JAM, Manzano GM. Manual de Eletroneuromiografia e potenciais evocados cerebrais para a pratica clinica. São Paulo, Brazil: Ateneu; 2007

27 Greene EC. The Anatomy of the Rat. New York, NY: Hafner; 1955

28 Thomander L, Aldskogius H, Grant G. Motor fibre organization in the intratemporal portion of cat and rat facial nerve studied with the horseradish peroxidase technique. Acta Otolaryngol 1982; 93(5-6):397-405

29 Wingerd BD. Rat Dissection Manual. Baltimore, MD: The Johns Hopkins University Press; 1988

30 Costa HJ, Bento RF, Salomone R, et al. Mesenchymal bone marrow stem cells within polyglycolic acid tube observed in vivo after six weeks enhance facial nerve regeneration. Brain Res 2013;13:10-21

31 Hubbard JH. The quality of nerve regeneration. Factors independent of the most skillful repair. Surg Clin North Am 1972;52(5): 1099-1108

32 Vasconcelos BCE, Gay-Escoda C. Facial nerve repair with expanded polytetrafluoroethylene and collagen conduits: an experimental study in the rabbit. J Oral Maxillofac Surg 2000;58(11):1257-1262

33 Miyamoto H. Introduction of axon packing density for histological quantitative assessment of peripheral nerve regeneration. Hiroshima J Anesthesia 1985;21(1):3-17
34 Donovan A. The nerve fibre composition of the cat optic nerve. J Anat 1967;101(Pt 1):1-11

35 Duncan D. A relation between axone diameter and myelination determined by measurement of myelinated spinal root fibres. J Comp Neurol 1934;60:437-471

36 Fernand VS, Young JZ. The sizes of the nerve fibers of muscle nerves. Proc Royal Soc 1951;139:38-58

37 Williams PL, Wendell-Smith CP. Some additional parametric variations between peripheral nerve fibre populations. J Anat 1971; 109(Pt 3):505-526

38 May M, Schaitkin BM. The Facial Nerve. 2nd ed. New York, NY: Thieme; 2000

39 Harrison DFN. Fibre size frequency in the recurrent laryngeal nerves of man and giraffe. Acta Otolaryngol 1981;91(5-6): 383-389

40 Mayhew TM, Sharma AK. Sampling schemes for estimating nerve fibre size. I. Methods for nerve trunks of mixed fascicularity. J Anat 1984;139(Pt 1):45-58

41 Mayhew TM, Sharma AK. Sampling schemes for estimating nerve fibre size. II. Methods for unifascicular nerve trunks. J Anat 1984; 139(Pt 1):59-66

42 Abercrombie M, Johnson ML. Collagen content of rabbit sciatic nerve during Wallerian degeneration. J Neurol Neurosurg Psychiatry 1946;9(4):113-118

43 Gundersen HJG. Notes on the estimation of the numerical density of arbitrary profiles: the edge effect. J Microsc 1977;111(2): 219-223

44 Salomone R, Bento RF, Costa HJ, et al. Bone marrow stem cells in facial nerve regeneration from isolated stumps. Muscle Nerve 2013;48(3):423-9

45 Ochi M, Noda M, Nakamitsu K, et al. Promotion of sciatic nerve regeneration in rats by a new neurotrophic pyrimidine derivative MS-430. Gen Pharmacol 1995;26(1):59-64 